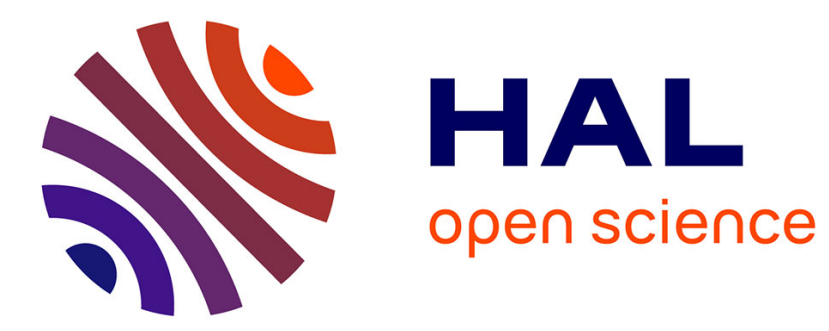

\title{
Trade and bank credit in a non-cooperative chain with a price-sensitive demand
}

Vincent Hovelaque, Jean-Laurent Viviani, Mohamed Ait Mansour

\section{To cite this version:}

Vincent Hovelaque, Jean-Laurent Viviani, Mohamed Ait Mansour. Trade and bank credit in a noncooperative chain with a price-sensitive demand. International Journal of Production Research, 2022, 60 (5), pp.1553-1568. 10.1080/00207543.2020.1866222 . hal-03127787

\section{HAL Id: hal-03127787 \\ https://hal.science/hal-03127787}

Submitted on 29 Mar 2021

HAL is a multi-disciplinary open access archive for the deposit and dissemination of scientific research documents, whether they are published or not. The documents may come from teaching and research institutions in France or abroad, or from public or private research centers.
L'archive ouverte pluridisciplinaire HAL, est destinée au dépôt et à la diffusion de documents scientifiques de niveau recherche, publiés ou non, émanant des établissements d'enseignement et de recherche français ou étrangers, des laboratoires publics ou privés. 


\title{
Trade and Bank Credit in a non-cooperative chain with a price-sensitive demand
}

Vincent Hovelaque, Jean-Laurent Viviani, Mohamed ait Mansour

Univ Rennes, CNRS, CREM - UMR 6211, Rennes, France

\section{ARTICLE HISTORY}

A later version is accepted in International Journal of Production Research

\begin{abstract}
The purpose of this article is to examine the impact of the working capital in the borrowing decision of a retailer. The proposed analysis is based on a model with a retailer, a supplier and a bank in a non cooperative game with a price-sensitive demand. The retailer, the supplier and the bank (if concerned) determine respectively the ordering quantity, the wholesale price and the interest rate. A Stackelberg game-theoretic approach is employed where the retailer is a follower and either the supplier or the bank is the leader. Some structural properties are first derived from the mathematical models. Then, some numerical simulations show that: (i) a trade credit garantees the same profits for the retailer and the supplier as in the case where the retailer has sufficient cash holdings, (ii) there exist some situations where the retailer has a better profit with a borrow than with sufficient cash holdings, (iii) borrowing decision depends on both retailer's and supplier's discount rate and the retailer's cash holdings.
\end{abstract}

\section{KEYWORDS}

Trade credit; Bank credit; Game theory; Supply chain finance; Inventory.

\section{Introduction}

The competitiveness of supply chains has been first studied through the optimization of physical and information flows through this chain (Gupta and Dutta, 2011; de Boer et al., 2015). The introduction of the financial dimension appears recently in the supply chain research area (for example, see the special Issue of M\&SOM coordinated by Babich and Kouvelis (2018)). This literature placed also emphasis on the importance of the interface between finance and operations management in order to insure the global competitiveness of one supply chain and, as proved for the management of physical flows, on the knowledge that the optimization of each individual's financial flows does not necessarily lead to the overall optimization of the whole supply chain financing.

Among the developed axes, the financing of working capital is one of the essential elements in the competitiveness of the supply chain. Empirical analysis shows that, in spite of the growth of new financing methods grouped under the concept of Supply Chain Finance (see Seifert et al. (2013) for a literature review on this topic), trade (internal to the supply chain) or/and bank (external to the supply chain) credits appear as the main financing tools of the supply chain. The objective of this paper 
is to compare the efficiency of these two most used financing modes in a context of strategic interactions between supply chain members and financial institutions.

Most of the previous studies on supply chain finance took place in a pure and perfect competition environment, both on the market of the end product, and on the capital market. It is worth mentioning that this assumption does not always correspond with the observed competitive structure of these two markets (Kouvelis and Zhao, 2017). Recent studies (Azar et al., 2019; Rym Ayadi et al., 2015) demonstrated that concentration in the banking industry in Europe and North America explains that banks can set loan rates above the competitive level in order to maximize their profit. A significant number of industries and specifically the retail industry are also highly concentrated in several countries (for instance Salhofer et al. (2011), Hovhannisyan et al. (2019)). In these industries, companies have a significant market power and take into account the impact of quantities sold on market prices. Moreover, the pure and perfect competitive framework does not permit a thorough analysis of the strategic behavior of various categories of stakeholders involved in the funding relationship: retailer, supplier, and bank. In this paper, we want to investigate weather the results on the best financing choices obtained under the pure perfect competition hypothesis would remain valid in an environment without perfect competition on the product and capital market. In this research direction, Wang and Zhang (2020) show how the heterogeneity of retailers (some are more financially constraint than others) affects the financial and operational decisions of the supply chain members. The objective of the paper is to examine, in this non yet explored environment, the determinants of the choice between three working capital financing modes: trade credit, bank credit and self-financing.

Numerous works in industrial economics and production research modeled the market demand by a deterministic curve depending on one or more parameters (price, quality, etc.). These approaches were popularized by the Nobel price in economy Jean Tirole (Tirole, 1988). Our approach is in this context, namely that of a price-dependent deterministic demand. In the context of supply chain financing, stochastic demand is relevant mainly if bankruptcy risk (and associated costs) represents a real concern (Kouvelis and Zhao, 2012). In our context of relationships between strategic suppliers and retailers (concentrated industries), the bankruptcy risk effect on the contractual financial relationship (we are in the case of short term financing) appears to us secondary compared to the dependence to price demand effect. For instance, in a sale and trade credit contract between Johnson \& Johnson and Walmart, the probability of default of Walmart seems of second order compared to the relationship between quantity and price of Johnson\& Johnson products. In our framework, the actors of the chain (distributor and industrial) seek to determine the optimal offer of final products by setting an optimal quantity, then the price is immediately determined. Moreover, our work focuses on the procurement financing strategy. We then do not take into account the short term issues of inventory management (trade off between inventory and frequency with the EOQ model).

We therefore propose a model where a capital constrained retailer faces one type of financing: bank credit and trade credit from his supplier. To take into account imperfect competition on the final market, we assume that the retailer faces a downward sloping demand curve (i.e. the demand is price-dependent). Roughly speaking, the retailer price decreases linearly with the quantities sold to the market (and conversely). The fact that the quantity is a decreasing function of price arises in the case of a monopoly on the final market or in a lesser extent by a monopolistic or an oligopolistic situation. In this context, operational decisions (choice of the optimal quantity to 
order) and financial decisions are interrelated, in contrast with the famous separation theorem of Modigliani and Miller (1959). Strategic interactions between the three players will be modeled by a non-cooperative game (Stackelberg game) in which the retailer is the follower and the supplier is the leader in the trade credit case, and, depending on the market structure, the bank or the supplier is the leader in the bank credit case. Even if the hypothesis of a deterministic demand erases the dimension of risk management (most models are placed under the newsvendor model), it allows us to obtain analyzable and comparable solutions in a new and untreated environment.

In this context of strategic interactions with three players, we derive the retailer's optimal order quantity, the wholesale price offered by the supplier as well as the optimal level of interest rate charged by the bank. We then analyze the best financing solutions for the three players involved in the supply chain by comparing their optimal profits in each case. Finally, through a numerical approach, we study the behavior of the solutions according to the model parameters, particularly the retailer's degree of financial constraint. Our main results are resumed as follows: (i) trade credit leads to the same profits for the retailer and the supplier as in the case where the retailer has sufficient cash holdings, (ii) there exist some situations where the retailer has a better profit with a bank credit than with sufficient cash holdings or trade credit, (iii) borrowing decision depends on both retailer's and supplier's discount rate and the level of retailer's cash holdings. Our results complement in a deterministic price-dependent demand context a previous work of Kouvelis and Zhao (2012) who compare bank credit with trade credit in the context of an independent stochastic demand. They claim that, as the supplier will have two control variables, the wholesale price and the commercial interest rate, she can offer a lower interest rate than the bank to the retailer and therefore trade credit is always preferred to bank credit. This result is in contrast with our result (ii). Jing et al. (2012); Yang and Birge (2013) demonstrate that, if the level of default risk is low, trade credit is preferred, however when the level of risk increases, supplier and retailer are willing to share the risk with a third party, which is the financial institution (bank credit) or a 3PL company.

This paper is organized as follows: Section 2 outlines the literature related to our work. Section 3 presents the theoretical models: three non-cooperative game using three major scenarios, (A) without borrowing, (F) trade credit and (B) bank credit. Section 4 displays the simulation and analyses some empirical results. Finally, some concluding remarks and perspectives end this article.

\section{Literature review}

In this paper, we develop an approach based on two main research streams: supply chain finance and a non-cooperative vertical coordination.

Management of financial flows in the supply chain has recently become an important center of interest for both professionals and academics (Pfohl et al., 2003), leading to the concept of Supply Chain Finance (SCF). SCF aims to study how to plan, manage and control the financial flow throughout the supply chain (Caldentey and Chen, 2009; Srinivasa and Mishra, 2011; Rhian and Paola, 2014; Yang and Birge, 2017 ) in order to optimize the financial flows and the allocation of financial resources in the supply chain to increase value (Hofmann et al., 2011). SCF research develops from analysing traditional internal to the supply chain (trade credit) and external (bank credit) financing modes to more recent ones such as electronic business platform 
financing (Wang et al., 2019), buyer financing (Deng et al., 2018), financially stronger partner's guarantee; supplier does not offer trade credit but a guarantee to help the retailer to obtain better financial conditions from its bank (Jin et al., 2019; Li and Jiang, 2020), and third-party-logistics providers' financing (Chen and Cai, 2011). More recently, Yu et al. (2020) try to assess the impact of platforms financing and blockchain technology on Supply Chain Finance.

The comparison between trade and bank credits has been intensively studied in the finance literature from the theoretical point of view (Burkart and Ellingsen, 2004) and the empirical point of view (Petersen and Rajan, 1997). From the theoretical point of view, the common explanation for trade credit is that suppliers have a monitoring advantage over banks, for example, in collateral value argued (Mian and Clifford, 1992), in liquidating collateral (Frank and Maksimovic, 2005), buyer/seller relationship (Wilner, 2000). Alternatively, sellers may have better information about firms than banks, and this will increase the capability of the institutions in evaluating and controlling the credit risk of their buyers (Schwartz and Whitcomb, 1977; Emery, 1987; Mian and Clifford, 1992; Freixas, 1993; Biais and Gollier, 1997; Jain, 2001). Moreover, trade credit is often used by US companies, especially small and medium enterprises (Petersen and Rajan, 1997; Berger and Udell, 1995; Wilner, 2000), European companies (Summers and Wilson, 2002), and in countries with less developed financial market (Booth et al., 2001). Trade credit becomes complementary to bank credit, in the case of a good economic environment (Yang and Birge, 2013) or to limit the supplier's risk exposure (Yang and Birge, 2017).

In spite of its interest, the financial literature did not address the problem of the interaction between financial and operations decisions. Research on this topic has been therefore developed to answer three interrelated questions: in which conditions financial and operational decisions are not independent? Can the financing conditions restore the efficiency of the chain? And what are the best possible financing methods? Considering the first question, Modigliani and Miller (1959) expressed that in a perfect capital market the financial and operations decisions can be separated. However, when market imperfections (such as bankruptcy costs, agency costs and information asymmetry) are taken into account, the irrelevance result no longer holds.

Buzacott and Zhang (2004) first integrated financial and operational decisions through the interactions between the physical flow and cash flow. After this seminal paper, numerous analysis have been based on the newsvendor's model with noncooperative coordination (Stackelberg game) between the supplier and the retailer. The research studies showed that the two decisions are interrelated when bankruptcy cost and the bankruptcy risk are taken into account in the bank financing process (Kouvelis and Zhao, 2012). Alan and Gaur (2016) showed that the borrower decision is affected by bankruptcy cost and demand information asymmetry. Dada and $\mathrm{Hu}$ (2008) demonstrated that finance and operations decision are also linked if the bank can set the interest rate in order to maximize profit. In the context of the newsvendor, Chen et al. (2019) analyze the default loss impact: it may increase the order quantity of the retailer but decrease the production quantity of the manufacturer, depending on the manufacturer's risk aversion. More recently, (Chen et al., 2020) show how commercial and financial decisions are interrelated in a dynamic setting.

In the second research direction, Lee and Rhee (2010) and Lee and Rhee (2011) examined if financing methods in combination with other coordination mechanisms (all-unit quantity discount, buybacks, two-part tariff, and revenue-sharing) can achieve supply chain coordination. They show that trade credit financing can help to achieve 
this coordination alone (Zhang et al., 2014) or in combination with bank financing (Yan et al., 2016). However, the coordination cannot be realized under bank credit financing alone. Phan et al. (2019) proposed a coordinating contract whith a capital constraint and a retailer's effort. This contract allows to improve the profitability of each member and of the supply chain.

The last research stream on the comparison between bank and trade credit financing is closely related to our research question. Cai et al. (2014) presented a model to analyze trade credit and bank credit with an exogenous wholesale price. In a paper closely related to ours, Kouvelis and Zhao (2012) analysis revealed that trade credit is cheaper than bank loan and the supplier can obtain higher profit in the trade credit scheme. Kouvelis and Zhao (2017) and Cheng et al. (2020) extend this work by taking into account the quality of the retailer, measured by the rating or the collateral level, and the differential attitude toward risk of banks and suppliers. They still show that retailer favours trade credit compared to bank financing, especially in the case of high-risk preference institutes.

Lots of studies have supposed a determinate market demand environment to investigate the role of trade credit financing with EOQ or EPQ models environment (Chen and Teng, 2015; Wu et al., 2014; Ouyang et al., 2013; Shah and Cárdenas-Barrón, 2015; Teng et al., 2012; Tiwari et al., 2016; Wu et al., 2016). Those researches introduced inventory and ordering costs and concentrated only on trade credit, but, in general, introduced neither a price dependent demand nor a comparison between trade credit and bank credit financing. Nevertheless, in a literature review on the news-vendor, Qin et al. (2011) recognized that depending upon the context, it could be argued that customer demand and price are interrelated.

The state of the art shows that the downward price effect of the quantity sold on the final market is not yet taken into account in the context of the choice between trade and bank credit. In the classical newsvendor framework, Lau and Lau (2003) found incoherent results when using different standard demand curves. Consequently, a linear price-dependant deterministic demand has been used in numerous articles (Chen and Kang, 2010; Huang, 2007; Corbett et al., 2004, etc.).

In summary, our paper complements existing literature by examining the financing of a supply chain with a supplier, a retailer and a bank. As in previous literature, the relations between the supplier and his client are non-cooperative, and are then analysed as a Stackelberg game in which the supplier (the leader) sets the wholesale price (to maximize his profit) by knowing the client's demand function (the follower). In contrast with most of previous SCF models that assume that the goods and services market is competitive, i.e. the price does not depend on the quantities offered by the firm (Lariviere and Porteus, 2001), we suppose that the price is a decreasing function of offered quantities. In the literature, it is also assumed that the bank (like the other players in the chain) is risk-neutral and that the credit supply is competitive, so that the interest rate is such that the bank's profit is equal to zero (Dammon and Senbet, 1988). In the same vein as Dada and $\mathrm{Hu}$ (2008), we suppose that the bank determines the level of interest rate by maximizing its profit function. The two main results achieved in the literature are firstly that external financing (trade or bank credit) makes it possible to recover the level of production without financial constraint, and secondly that commercial credit is generally preferable to bank financing. In comparison, we demonstrate that the profit of the retailer can be, in the case of bank credit, higher to the one obtained without financial constraint and that in consequence bank credit could be preferred to trade credit. In short, the contribution of the paper is to 
analyse the choice, by a retailer, between bank and trade credit when the conditions of pure and perfect competition are not satisfied in the goods and in the credit market. We demonstrate that the choice between the two financing modes could be different to the one already obtained in the literature in a pure and perfect competition context.

\section{The model}

We consider a single-product supply chain with one supplier $(S)$ and one retailer $(R)$. The retailer faces a market demand expressed by a classical stylized linear function of price $q=a-b p$ (Ghosh and Shah, 2012), with $a$ market size and $b$ price elasticity, strictly positive parameters. Classically (basic model), the retailer has to maximize his profit function $\Pi_{R}(q)=(p-w) q$ where $w$ is the wholesale price given by the supplier (acting as the Stackelberg leader). In this case, $q(w)=(a-b w) / 2$ corresponds to the optimal order quantity. Then, the supplier determines his optimal wholesale price with $\Pi_{S}(w)=(w-c) q(w)$, where $c$ is the supplier's marginal production cost. Optimal values are derived as follows: $w^{*}=(a+b c) / 2 b$ and $q^{*}=(a-b c) / 4$, the feasability of the model guaranted when $a \geq b c$. The total purchase cost for the retailer is then: $w^{*} q^{*}=\left(a^{2}-b^{2} c^{2}\right) / 8 b$. As expected, quantity is a positive function of the market size and a negative function of price elasticity and production cost. The wholesale price is a positive function of these three parameters.

We try to examine the retailer's ability to finance this purchase cost. $T$ is therefore defined as the retailer's available cash holdings (working capital). Then, if $T \geq w^{*} q^{*}$, the retailer has enough internal cash to finance his purchase (scenario A). In the other case, three scenarios are considered: the retailer finances his purchases at the level of his cash holdings (sc I); the retailer uses a commercial credit from the supplier (sc $\mathrm{F}$ ); the retailer uses a bank credit from a bank (sc B1 or B2). We compare these four scenarios when some key parameters change and not to determine which scenario is the best for each actor. In such a case, if a stakeholder can determine which scenario to choose, this actor would act as a leader of each scenario.

In the sequel, we determine the optimal programs for each scenario; the conditions of the first and second order are checked in the appendix. In all cases, there are no supply/inventory/delivery constraints, but perfect information. Moreover, the monetary exchanges will be in 2 steps: at "time 0" (resp. "time 1") before (resp. after) the market sales. To take into account these two times, each player supports a discount factor $\tau_{i}=\left(1+t_{i}\right)^{-1}$ where $t_{i} \geq 0$ is the interest rate $(i=R, S, B)$. We use the superscript * to denote the optimal values and functions, and the underscript $X$ and/or $Y$ where $X$ indicates the player considered $(R, S, B)$ and $Y$ indicates the scenario $(A, I, F, B 1, B 2)$.

\subsection{Scenarios $A$ and I: no borrowing}

In these scenarios, first, the supplier defines a unit wholesaler price, then the retailer determines the order quantity $q$ that will be only funded with his own cash holdings $T$. The game is then solved backwards to ensure optimality of each sub game. At time 0 , the retailer will pay $\min \{w q ; T\}$ to the supplier and will receive $p q$ at time 1 . Then the retailer solves the following maximization problem:

$$
\max _{q} \Pi_{R}=\left(p \tau_{R}-w\right) q .
$$


Substituting $p=(a-q) / b$ into the above profit function and solving the first-order conditions (FOC) yield the retailer's order quantity:

$$
q(w)=\frac{a \tau_{R}-b w}{2 \tau_{R}} .
$$

Anticipating this order quantity, the supplier will optimize his profit function knowing that he will receive $\min \{w q ; T\}$ from the retailer and pays $c q$ to his upstream market at time 0 . The supplier's profit function is thus as follows:

$$
\max _{q(w)} \Pi_{S}=(w-c) q(w) \text { such that } T \geq w q(w) .
$$

Note that $\tau_{S}$ is missing because all monetary flows take place at time 0 for the supplier. This problem is solved with a Lagrangian function. Respecting the first and second order conditions of Kuhn-Tucker and the condition $a \tau_{R} \geq b c$, we obtain two situations: either $T \geq T_{A}=w_{A}^{*} q_{A}^{*}=\left(a^{2} \tau_{R}^{2}-b^{2} c^{2}\right) /\left(8 \tau_{R} b\right)$ and the retailer purchases his optimal quantity with a wholesale price $w_{A}$, or $T<T_{A}$ and the retailer purchases $q_{I}^{*}=T / w_{I}^{*}$. This result is summarized in the following Proposition:

Proposition 3.1. Considering that $a \tau_{R} \geq b c$ and $T_{A}=\left(a^{2} \tau_{R}^{2}-b^{2} c^{2}\right) /\left(8 \tau_{R} b\right)$, the optimal values are given by:

- if $T \geq T_{A}$, then $w_{A}^{*}=\frac{a \tau_{R}+b c}{2 b}$ and $q_{A}^{*}=\frac{a \tau_{R}-b c}{4 \tau_{R}}(S c A)$

- if $T<T_{A}$, then $w_{I}^{*}=\frac{a \tau_{R}+\sqrt{\left(a \tau_{R}\right)^{2}-8 \tau_{R} b T}}{2 b}$ and $q_{I}^{*}=\frac{a \tau_{R}-\sqrt{\left(a \tau_{R}\right)^{2}-8 \tau_{R} b T}}{4 \tau_{R}}$ (Sc I)

Optimal profit functions are derived as follows:

- Sc A : $\Pi_{S A}^{*}=\frac{\left(a \tau_{R}-b c\right)^{2}}{8 b \tau_{R}}$ and $\Pi_{R A}^{*}=\frac{\left(a \tau_{R}-b c\right)^{2}}{16 b \tau_{R}}$

- Sc I : $\Pi_{S I}^{*}=T-\frac{c}{4 \tau_{R}}\left(a \tau_{R}-\sqrt{\left(a \tau_{R}\right)^{2}-8 b \tau_{R} T}\right)$ and $\Pi_{R I}^{*}=\frac{\left(a \tau_{R}-\sqrt{\left(a \tau_{R}\right)^{2}-8 b \tau_{R} T}\right)^{2}}{16 b \tau_{R}}$

When the retailer has enough cash (Scenario A) the solutions are similar to those of the basic case but take into account the discount factor. The wholesale price decreases when the discount rate increases, contrary to the optimal order quantity. When the cash constraint is binding (Scenario I), the order quantity, the wholesale price and the profits increase with the level of cash. The solutions of the two scenarios become identical for $T=T_{A}$.

\subsection{Scenario F: supplier's loan}

If the retailer has insufficient initial cash $(T<w q)$, the supplier offers a trade credit. The retailer's purchase will be paid in two stages (at time $t=0$ and $t=1$ ). Therefore, the supplier proposes a wholesale price $w_{0}$ (resp. $w_{1}$ ) at the beginning $t=0$ (resp. at the end $t=1$ ) of the selling season. The ratio $\frac{w_{1}}{w_{0}}$ gives the interest rate charged by the supplier. With these two wholesale prices, the retailer chooses his order quantity $q$ and the two payments at time $t=0\left(\alpha w_{0} q\right)$ and $t=1\left((1-\alpha) w_{1} q\right)$. Then the retailer's profit function is defined as follows: $\Pi_{R F}=q p \tau_{R}-q\left(\alpha w_{0}+(1-\alpha) w_{1} \tau_{R}\right)$ under the constraint $\alpha w_{0} q \leq T$. With this quantity and payment's share, the supplier will maximize his profit function: $\Pi_{S F}=w_{0} \alpha q\left(w_{0}, w_{1}\right)+(1-\alpha) w_{1} q\left(w_{0}, w_{1}\right) \tau_{S}-c q\left(w_{0}, w_{1}\right)$.

This problem is solved recursively and gives a unique solution summarized in the next 
Proposition.

Proposition 3.2. If $\tau_{R}<\tau_{S}$ or $a \tau_{S} \leq b c$, then no agreement exists. Otherwise, when $\tau_{R} \geq \tau_{S}$ and $a \tau_{S}>b c$, a trade credit is obtained with the following optimal values:

- $q_{F}^{*}=\frac{a \tau_{S}-b c}{4 \tau_{S}}, \alpha=\frac{8 b \tau_{S}^{2} T}{\left(\left(a \tau_{S}\right)^{2}-(b c)^{2}\right) \tau_{R}}$

- $w_{0 F}^{*}=\tau_{R} w_{1 F}^{*}, w_{1 F}^{*}=\frac{a \tau_{S}+b c}{2 b \tau_{S}}$

Optimal profit functions are derived as follows:

- $\Pi_{R F}^{*}=\frac{\left(a \tau_{S}-b c\right)^{2} \tau_{R}}{16 b \tau_{S}^{2}}=\frac{\left(a \tau_{S}-b c\right)^{2}}{16 b \tau_{S}} \beta$

- $\Pi_{S F}^{*}=\frac{\left(a \tau_{S}-b\right)^{2}}{8 b \tau_{S}}+T\left(1-\frac{1}{\beta}\right)$ with $\beta=\tau_{R} / \tau_{S}$.

The Proposition leads to several remarks. In the optimization process, the retailer is indifferent to the payment's share $\alpha$ as soon as $\alpha w_{0} q \leq T$. The best share for the supplier is the value obtained in Proposition 3.2 such that the cash holding's condition is saturated, that is $\alpha^{*} w_{0}^{*} q_{F}^{*}=T$. This result can also be explained by the prices relation $w_{1} \tau_{R}=w_{0} \geq w_{1} \tau_{S}$. The interest rate charged by the unconstrained working capital supplier equals the retailer's discount rate, similar to the result of Kouvelis and Zhao (2017) where, in the trade credit, the supplier charged zero interest rate when his credit rating is higher than the threshold. The supplier then prefers to be paid at $t=0$. The retailer's optimal profit is independent of the cash holding level due to the fact that $w_{0 F}^{*}=\tau_{R} w_{1 F}^{*}$.

If $\tau_{S} \leq \tau_{R}$, then $\Pi_{R F}^{*} \leq \Pi_{R A}^{*}, \Pi_{S F}^{*} \leq \Pi_{S A}^{*}$ and $q_{F}^{*} \leq q_{A}^{*}$. This result is consistent with the fact that insufficient cash holdings lowers the profit of each player in the chain. The proportion paid at time $0(\alpha)$ increases with the cash holdings until $T=T_{A}$ where $\alpha=1$. Confirmed by Kouvelis and Zhao (2017), when the retailer has sufficient cash, he prefers the upfront payment.

The above solutions match with the solutions of scenario $\mathrm{A}$ if $\tau_{R}=\tau_{S}$. In this case, $S$ determines his prices to incite $R$ to order $q_{F}^{*}=q_{A}^{*}$. In that case, $w_{F 1}^{*}=\frac{1}{\tau_{S}} w_{A}^{*}$ is the future value of the wholesale price at time 0 .

Notice that there are two parts in the supplier's profit function namely the operational part $\frac{\left(a \tau_{S}-c b\right)^{2}}{8 \tau_{S} b}$ and the financial part $T(1-1 / \beta)$ due to borrowing. If $\left(\tau_{R}-\tau_{S}\right) \longrightarrow 0$, then $\beta \longrightarrow 1$; in other words, when the retailer's discount rate is equivalent to supplier's discount rate there is not financial part for supplier.

If $\tau_{R} \leq \tau_{S}$, the supplier obtains a financial gain otherwise, he suffers a financial loss.

Proposition 3.3. Supplier's profit function increases with retailer's discount rate $\tau_{R}$. The retailer's order quantity increases with supplier's discount rate $\tau_{S}$ whereas the wholesale price decreases.

The total purchase for the retailer in scenario $\mathrm{F}$ is $w_{S}^{*} q_{F}^{*}=\frac{\left(a \tau_{S}\right)^{2}-(b c)^{2}}{8 b \tau_{S}^{2}}+T\left(1-\frac{1}{\tau_{R}}\right)$. Then, there exists a threshold of supplier's credit defined by $T_{F}=\frac{\left(a \tau_{S}\right)^{2}-(b c)^{2}}{8 b \tau_{S}^{2}} \tau_{R}$. Notice that $T_{F} \leq T_{A}$, with equality for $\tau_{S}=\tau_{R}$. Moreover, if $T<T_{F}$, the structural constraint $T<w q$ is verified.

In short, there are three successive scenarios depending on the cash holdings level: if $T \leq T_{F}$, then the retailer is financed by the supplier; if $T_{F}<T<T_{A}$, then the retailer is financially constrained and uses all his cash holdings for his purchase; finally, if $T \geq T_{A}$, the retailer has enough cash holdings to purchase his optimal quantity as in the unconstrained case. Moreover, there is no jump between the three successive 
scenarios: $\Pi_{R I}^{*}\left(T_{F}\right)=\Pi_{R F}^{*}$.

\subsection{Scenarios B1 and B2 : bank loan}

In this subsection, the retailer may borrow from a bank. Two cases are described: either the bank is leader of the chain (and the supplier sub-leader), or the supplier is leader and the bank is sub-leader.

\subsubsection{Scenario B1 with bank leader}

The retailer may borrow from a bank which is the leader of the game (the supplier will be considered as a sub-leader). In this case, the bank sets its interest rate $r_{B 1}$, then the supplier determines his wholesale price $w_{B 1}$, and finally, the retailer commands his order quantity $q_{B 1}$. This scenario occurs if $T<w q$ and the bank loan is then $w q-T$. The retailer's profit function is $\Pi_{R B 1}=p q \tau_{R}-T-(w q-T) \tau_{R}\left(1+r_{B 1}\right)$ which is optimized for $q_{B 1}=\frac{a-b w\left(1+r_{B 1}\right)}{2}$ under the constraint $T<w q_{B 1}(w)$. Therefore, the supplier's profit function $\Pi_{S B 1}=(w-c) q(w)$ is maximized for $w_{B 1}=\frac{a+b c\left(1+r_{B 1}\right)}{2 b\left(1+r_{B 1}\right)}$. We consider that the bank's optimization is expressed by: $\operatorname{Max} \Pi_{B B 1}=-\left(w_{B 1} q_{B 1}-\right.$ $T)+\left(w_{B 1} q_{B 1}-T\right)\left(1+r_{B 1}\right) \tau_{B}$, the bank profit will verify the following condition: $T<w_{B 1} q_{B 1}$ (the condition to make a borrowing decision) and $1 \leq\left(1+r_{B 1}\right) \tau_{B}$ (it guarantees a positive bank payoff).

The second constraint involves a positive bank's profit function. With a Lagrangian approach, $r_{B 1}$ must verify the following equation:

$$
2 \tau_{B}(b c)^{2}\left(1+r_{B 1}\right)^{3}+\left(8 b T \tau_{B}-(b c)^{2}\right)\left(1+r_{B 1}\right)^{2}-a^{2}=0
$$

This third order equation can be solved using the Cardan method but $r_{B 1}^{*}$ is quite complex to derive analytically. Nevertheless, using the implicit function theorem, some behaviors of $r_{B 1}^{*}$ can be described.

Proposition 3.4. The bank's interest rate decreases with the bank's discount rate factor and with retailer's cash level. The bank's interest rate is independent of retailer's discount factor.

In this case, the retailer may use a bank credit if the following condition is verified: $T<T_{B 1}=w_{B 1} q_{B 1}=\frac{\left(a \tau_{B 1}\right)^{2}-(b c)^{2}}{8 b \tau_{B 1}}$.

\subsubsection{Scenario B2 with supplier leader}

The retailer may borrow from a bank which is the sub-leader (the supplier will be considered as a leader). In this case, the supplier determines its wholesale price $w_{B 2}$, then the bank sets its interest rate $r_{B 2}$, and finally, the retailer commands his order quantity $q_{B 2}$. This scenario arises if $T<w_{B 2} q_{B 2}$ and the bank loan is then $w_{B 2} q_{B 2}-T$. The retailer's profit function is $\Pi_{R B 2}=p \tau_{R} q_{B 2}-T-\left(w_{B 2} q_{B 2}-T\right) \tau_{R}\left(1+r_{B 2}\right)$ and is optimized for $q_{B 2}=\frac{a-b w_{B 2}\left(1+r_{B 2}\right)}{2}$. Consequently, the bank's profit function $\Pi_{B B 2}=$ $-\left(w_{B 2} q_{B 2}-T\right)+\left(w_{B 2} q_{B 2}-T\right)\left(1+r_{B 2}\right) \tau_{B}$ is maximized for $\left(1+r_{B 2}\right)=\frac{a \tau_{B}+b w_{B 2}}{2 b w_{B 2} \tau_{B}}-\frac{T}{b w_{B 2}^{2}}$ under the constraint: $T<w_{B 2} q_{B 2}$. Finally, the supplier's optimization is as follows: $\operatorname{Max} \Pi_{S B 2}=\left(w_{B 2}-c\right) q_{B 2}$. The optimal wholesale price $w_{B 2}$ verifies the following 
equation:

$$
-2 b w_{B 2}^{3}+w_{B 2}^{2}\left(b c+a \tau_{B}\right)+2 c T \tau_{B}=0
$$

The optimal wholesale price is the root of a third order equation and is not simple to express analytically. Some behaviors are proposed in the next Proposition.

Proposition 3.5. The optimal wholesale price and the total purchase of the retailer increase with the cash T. Moreover, the retailer may use a bank credit if the cash is below a maximum threshold $T_{B 2}$.

\section{Numerical analysis}

We will compare different profits and control variables (quantity and wholesale price) in two different cases, when all discount factors are equal to 1 and when they are all different. The major decisions steps are the following: the supplier determines its optimal wholesale price $w^{*}$, then the retailer its optimal quantity $q^{*}$. In function of the scenario, the bank proposes its optimal interest rate $r_{b}^{*}$. These optimal values allow to compute the profit of each member of the chain.

\subsection{Discount rates equal to 1}

Consider that $a=20, b=2, c=3$ and $\tau_{R}=\tau_{S}=\tau_{B}=1$. The following five figures represent, for different values of $T$, wholesale price, quantity, and retailer, supplier and bank profits. Analysis of the figures calls for various remarks.

First of all, with a trade credit, the supplier offers a price contract that leads to the same optimal wholesale price and quantity than those obtained when the retailer had sufficient cash holdings (comparing scenarios $\mathrm{F}$ and $\mathrm{A}$ in Figures 1 and 2). This result is consistent with Propositions 3.1 and 3.2 when discount rates equal 1.

Secondly, with a bank credit, there exists a segment $\left\{T^{\prime} ; T_{A}\right\}$ for which the retailer's profit is greater than in scenario A (figure 3). Conversely, the supplier's profit (Figure 4 is negatively impacted by the bank credit in both cases (bank leader and subleader). The first point can be explained analytically. If $T$ tends to $T_{A}$, then $r_{B}$ tends to 0 . Moreover:

$$
\frac{\partial \Pi_{R B 1}}{\partial T}=-1+\frac{1}{16 b}\left(16 b\left(1+r_{B}+T \frac{\partial r_{B}}{\partial T}\right)+4 b^{2} c^{2} r_{B} \frac{\partial r_{B}}{\partial T}-2 a b c \frac{\partial r_{B}}{\partial T}\right)
$$

Then:

$$
\lim _{\substack{T \rightarrow T_{A} \\ r \rightarrow 0}} \frac{\partial \prod_{R B 1}}{\partial T}=\frac{\partial r_{B}}{\partial T}\left(T_{A}-\frac{a c}{8}\right)
$$

With Proposition 3.4, the derivative of $\Pi_{R B 1}$ is negative with $T$ when $T$ tends to $T_{A}$. Consequently, the retailer's profit is higher in a bank configuration when $T$ is lower than $T_{A}$. 
Third, the bank prefers to act as the leader than as the subleader (Figure 5). The retailer will never choose bank credit when the bank is sub-leader (comparison of scenarios B1 and B2). In fact, when the supplier is leader, he increases his wholesale price and then captures the added-value (Figure 2). The most interesting case is when the bank is leader (scenario B1), hence the retailer's financing choice depends on his cash level. When the level of cash is low (below $T^{\prime}$ ) the retailer will choose trade credit. That can be explained by the fact that when the level of cash holdings is low, the bank rate is high (see proposition 3.4.). Moreover in subsection 3.2., we demonstrate that the interest rate offered by the supplier is independent of $T$.

Lastly, the supplier suffers from the competition with the bank. When the retailer chooses the bank credit (scenario B1), the supplier profit increases with the cash level but is always lower than with the trade credit (Figure 4). Thereby, the bank credit impacts the wholesale price as shown in Figure 2.
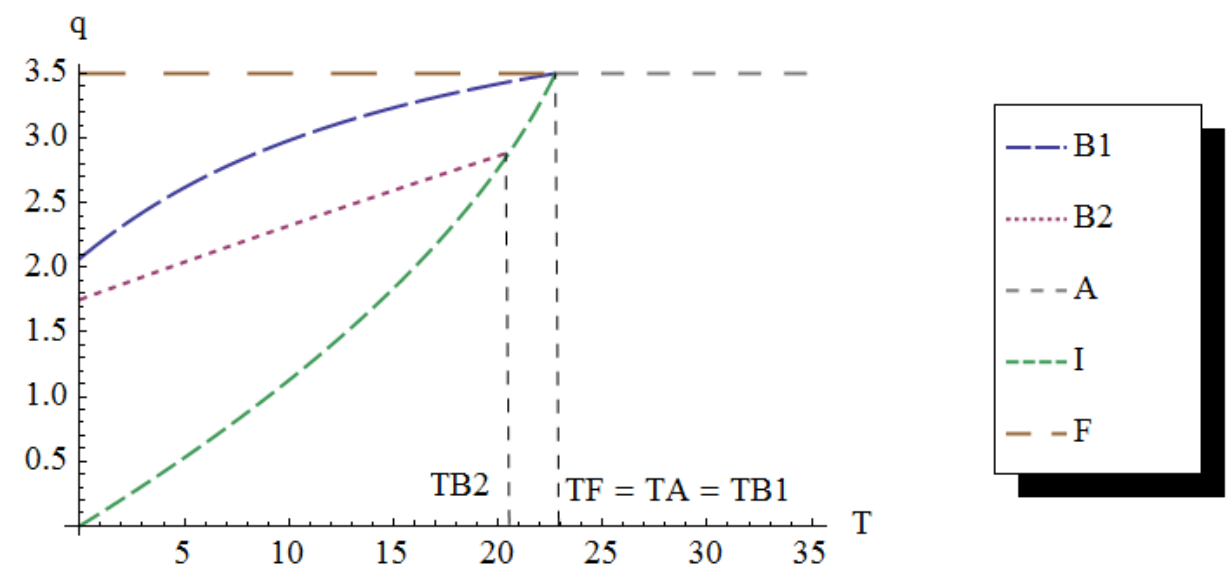

Figure 1.: The retailer's order quantity
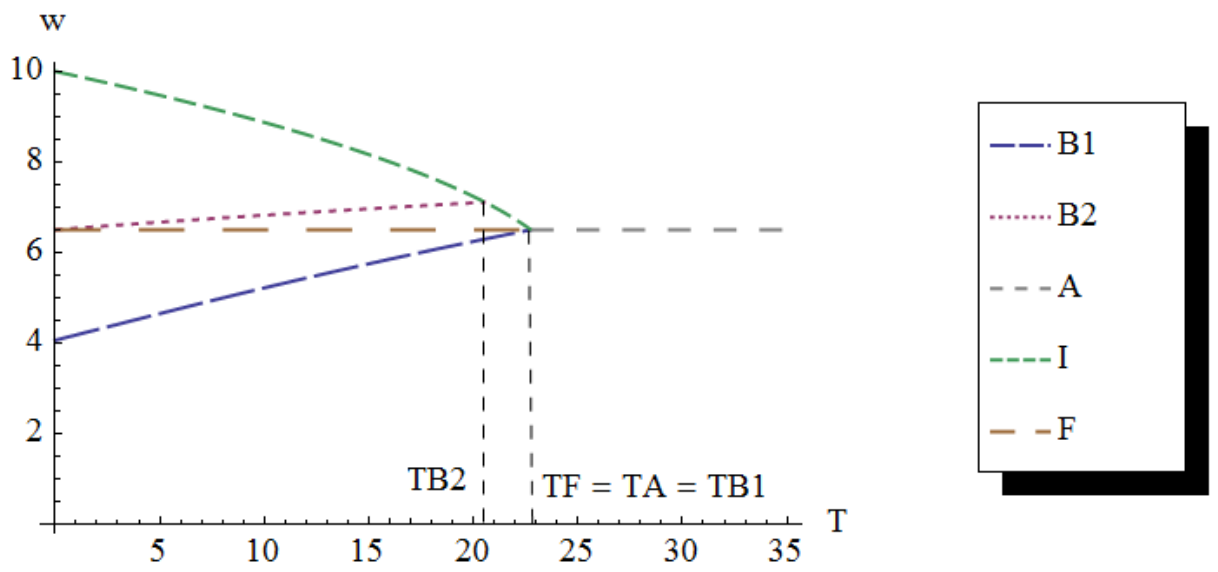

Figure 2.: The supplier's wholesale price 

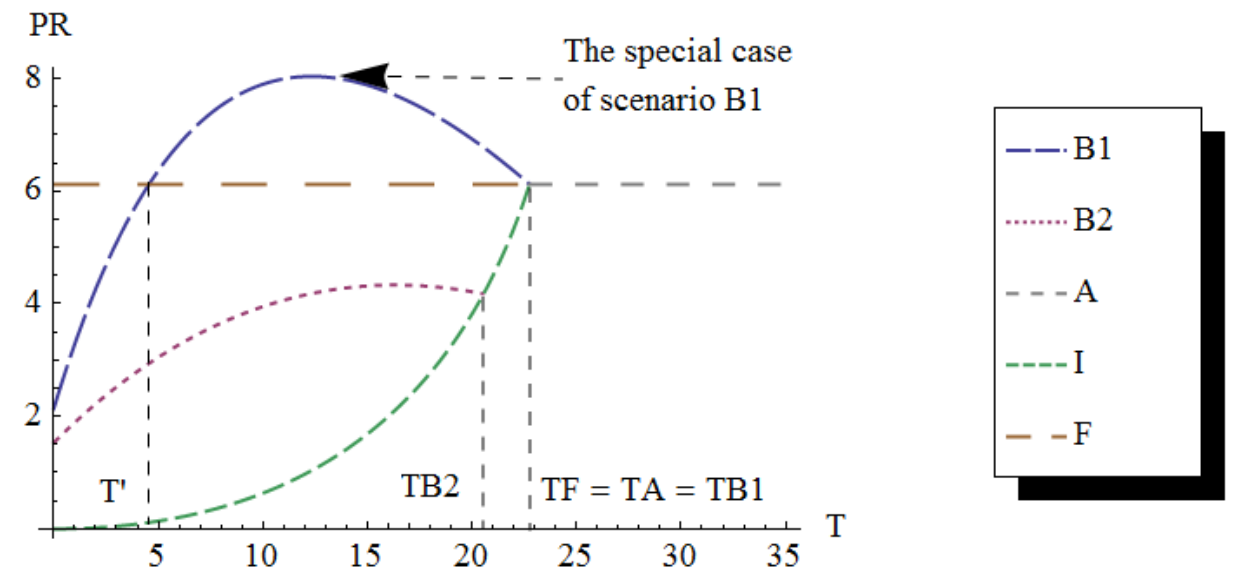

Figure 3.: The retailer's profit function

PS
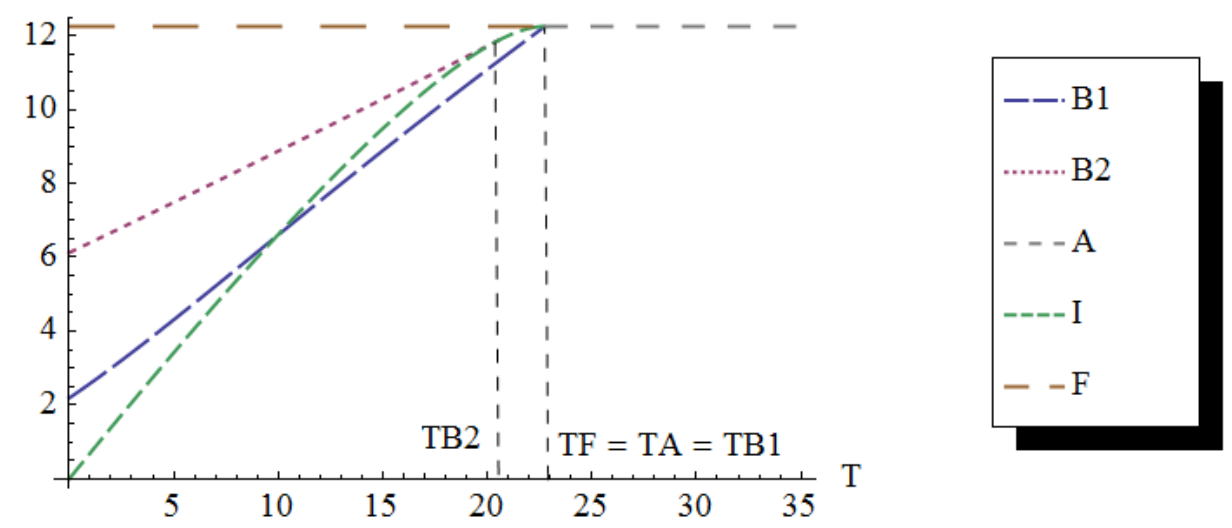

Figure 4.: The supplier's profit function

PB

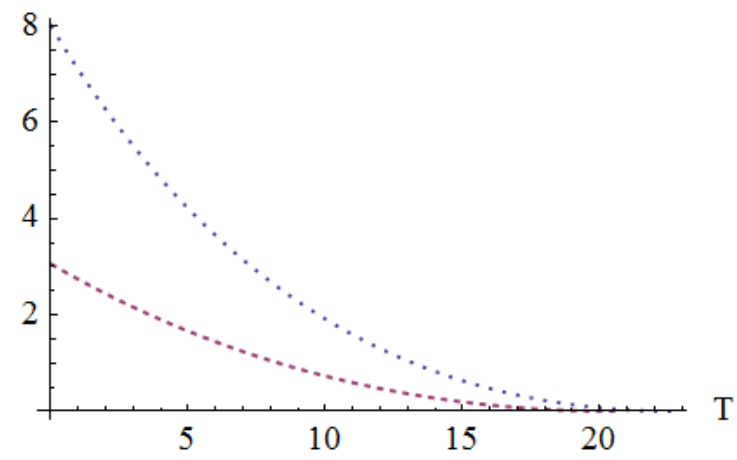

Figure 5.: The bank's profit function

\subsection{Different discount factors}

In this section, we investigate the impact of discount factors on the supply chain financing. We investigate successively the impact of supplier/retailer discount factor 
and the impact of bank discount factor. We also first assume that the opportunity of the bank's cost capital is lower (equal to zero i.e $\tau_{B}=1$ ) than those of the two other members of the chain with $\tau_{R}>\tau_{S}$ (proposition 3.2). The last experimentation is focused on the bank rate's behavior if the bank discount factor varies.

Given $a=20, b=2, c=3$ and $\tau_{R}=0.8, \tau_{S}=0.5, \tau_{B}=1$, we illustrate the result on the retailer's profit (figure 6).
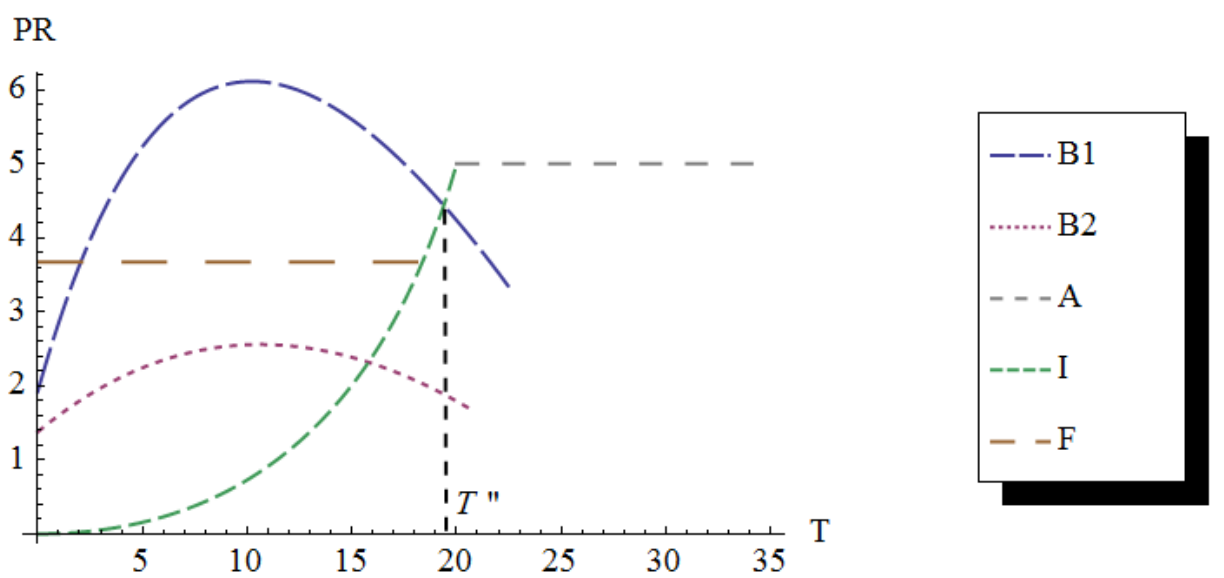

Figure 6.: The retailer's profit function $\left(\tau_{B}>\tau_{R}>\tau_{S}\right)$

As explained in section 3, the difference between the retailer's discount rate and the supplier's discount rate causes an increase or a decrease in the retailer's profit when $R$ uses trade credit.

We observe on Figure 6 that the choice of external financing (trade credit, bank credit) depends on the level of the discount rate factors. By comparing Figure 3 and 6 , we conclude that bank credit is preferred to trade credit irrespective of the cash holdings level. However, depending on whether or not the cash level is above $T^{\prime \prime}$ the retailer will prefer or not to use external financing.

When the discount rates are different, the trade credit does not generate the same retailer's profit than in scenario A even if the same quantity is ordered. Bank credit worsens the situation of the final consumer. In all scenarios the order quantity increases with $T$. Figure 7 shows that when the bank is leader it forces the supplier to reduce his wholesale price in case of bank credit (scenario B1), which explains the reduction of the supplier's profit in Figure 4. However, if the supplier remains the leader, it maintains or even increases its wholesale price. In Figure 7, we observe that the bank's interest increases with the amount of the loan. This finding confirms that the bank profit decreases with the retailer's cash holdings. When the retailer has sufficient cash, the bank loan will not be interesting for retailer's business, and the bank will decreases its interest rate significantly to attract the retailer. 


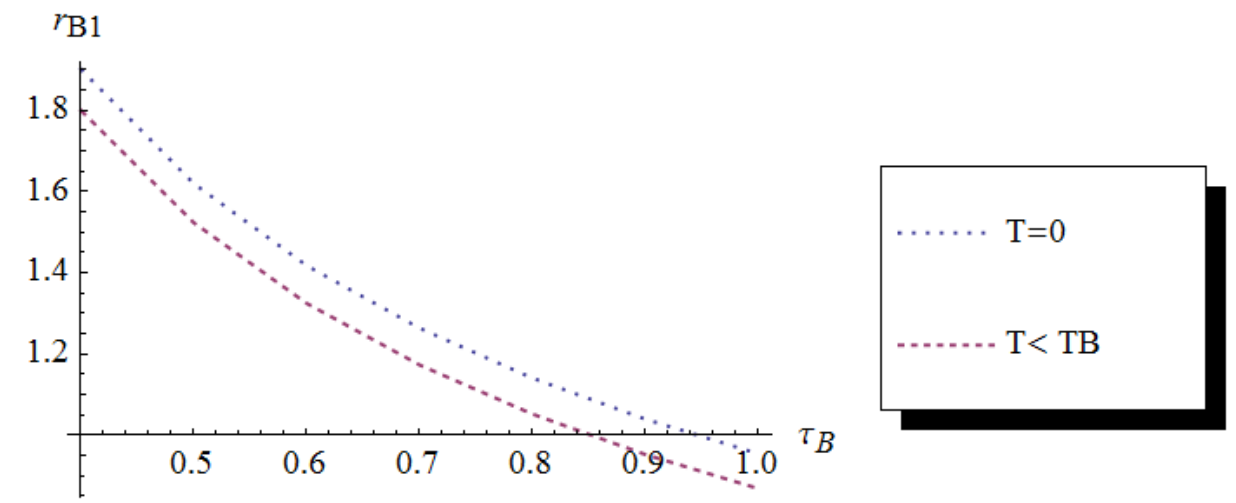

Figure 7.: Bank interest rate with discount rate factor

\subsection{Further testings}

In order to investigate the impact of market size, $a$, and price elasticity, $b$, on the choice of the optimal financing mode, we analyse first the scenarios when $T=0$ and $\tau_{R}=\tau_{S}=\tau_{B}=1$. In that case, results of Scenario $\mathrm{F}$ is obtained from Proposition 3.2 and, as Equations 1 and 2 are simpler to solve, optimal decision variables and profits can be derived as follows:

\begin{tabular}{|l|c|c|c|}
\hline & Scenario $F$ & Scenario $B 1$ & Scenario B2 \\
\hline$\Pi_{R Y}$ & $\frac{(a-b c)^{2}}{16 b}$ & $\frac{(6 a-b c \Psi)^{2}}{576 b}$ & $\frac{(a-b c)^{2}}{64 b}$ \\
\hline$\Pi_{S Y}$ & $\frac{(a-b c)^{2}}{8 b}$ & $\frac{(6 a-b c \Psi)^{2}}{48 b \Psi}$ & $\frac{(a-b c)^{2}}{16 b}$ \\
\hline$\Pi_{B Y}$ & & $\frac{(\Psi-6)\left(36 a^{2}-b^{2} c^{2} \Psi^{2}\right)}{288 b \Psi}$ & $\frac{(a-b c)^{2}}{32 b}$ \\
\hline
\end{tabular}

with $\Psi$ as a parameter representing an inelegant expression function of $a, b$ and $c$. Some existing constraints on $\Psi$ can be expressed but are not detailed here (quantities, wholesaler price and profits have to be positive). As a first comment, scenarios $\mathrm{F}$ and B2 have the same behavior: the leader earns twice as much as the follower (which earns twice as much the retailer in B2). This is consistent with the well-known notion of double marginalization popularized by (Tirole, 1988). Moreover, the supply chain profit is greater in scenario F than in scenario B2. As the supplier acts as a leader in these two scenarios, he would prefer to offer a trade credit and to reject the bank credit option. Moreover, the retailer has a better profit in scenario $\mathrm{F}$ than in scenario B2. This is consistent with results of Kouvelis and Zhao (2012) stating that trade credit is preferred to bank credit.

As a second comment, for further numerical analysis, all profits (retailer, supplier and bank) increase with the market size $a$ and decrease with elasticity $b$ as shown in Figures 8 and 9 (with $c=3, a=20$ and $b=1.5$ ). $\Pi_{R F}$ always dominates $\Pi_{R B 1}$ and $\Pi_{R B 2}, \Pi_{S F}$ always dominates $\Pi_{S B 2}$ and $\Pi_{S B 1}$ and $\Pi_{B B 1}$ always dominates $\Pi_{B B 2}$. These dominances are becoming greater (resp. lower) as the market (resp. elasticity) grows. 

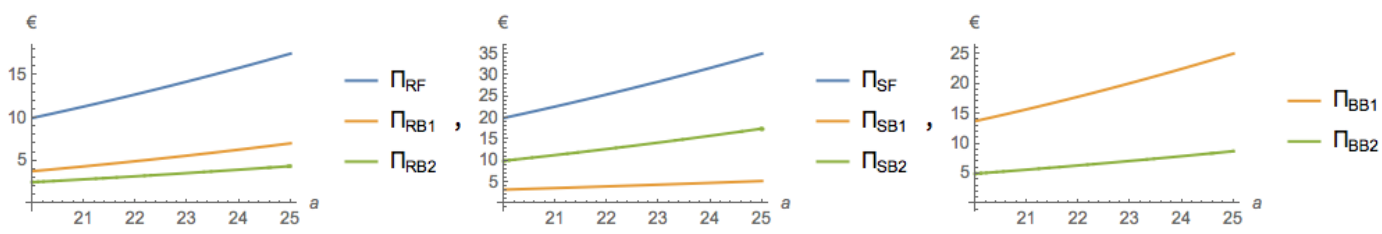

Figure 8.: Profit behavior when $a$ increases and $T=0$
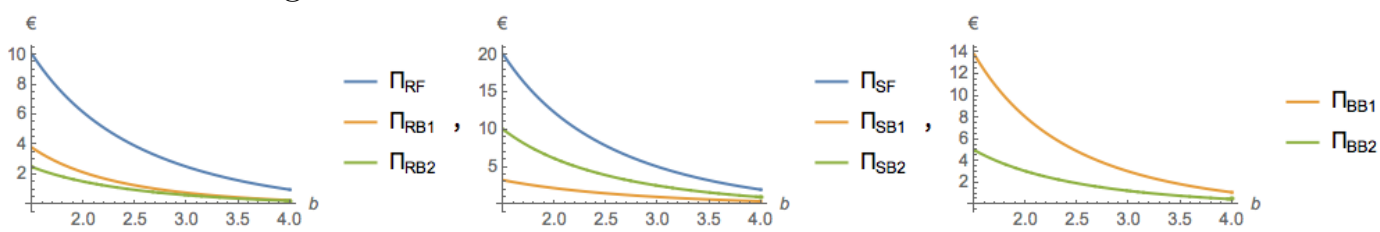

Figure 9.: Profit behavior when $b$ increases and $T=0$

Last results do not hold for all values of $T$. For example, if $T=6$, Figure 10 shows that a bank credit B1 is preferred to a trade credit $\mathrm{F}$ for low values of $a$. In fact, the larger the market is, the larger the order quantity is, and therefore, the higher the purchase cost is. The difference between this cost and the level of $T$ determine the level of the financing needs of the retailer. This result is consistent with Figure 3. All things otherwise being equal, the larger $T$ compared to the market size is $(T<$ $T_{A}=T_{F}=T_{B 1}$ ), the lower the financing need of the retailer, and the more Scenario $B 1$ is preferred. When retailer cash holding increases it becomes closer to $a c$ which corresponds to the maximal cost production for the first actor of the chain. This result indicates that the retailer would prefer a bank credit if its financing requirement is relatively low (cash holding relatively high) compared to the market size. We could find a numerical case where the hierarchy of financing is modified with elasticity $b$.
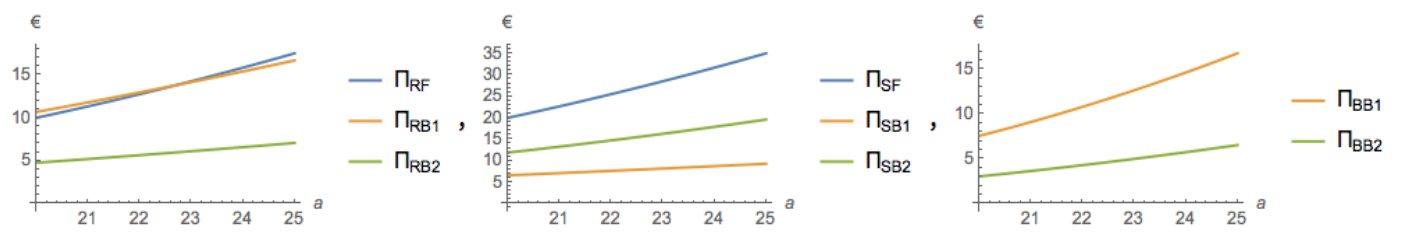

Figure 10.: Profit behavior when $a$ increases and $T=6$
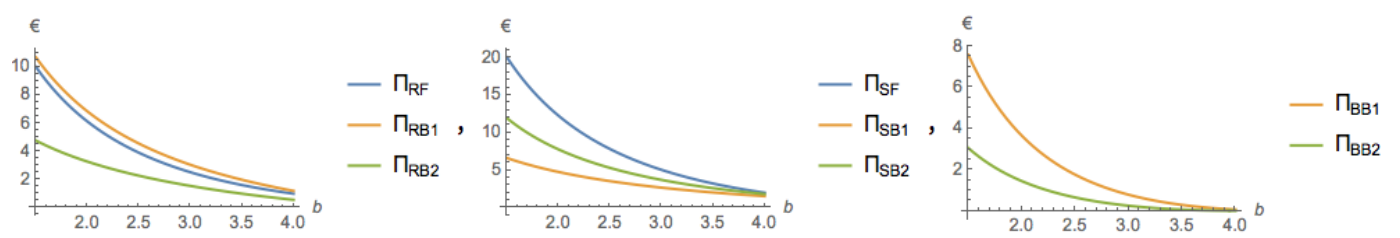

Figure 11.: Profit behavior when $b$ increases and $T=6$

\section{Conclusion}

In this paper, we develop different scenarios to examine the impact of the level of working capital on the retailer in the case of trade credit and bank credit financing. We demonstrated the existence of cash holdings and discount rates impact on the retailer's borrowing mode choice, and the impact of the game theory's role on the players' profit in the supply chain. Under a constrained capital, retailer orders less 
than with sufficient cash. However, the retailer benefits from a lower wholesale price, which will allow him to generate significant profit. Using trade credit the supply chain achieves profit equivalent to the supply chain without capital constraint.

Furthermore, when the bank participates in the supply chain as an active agent and in the non-competitive finance market (Stackelberg game), the bank generates profit. If the financing need of the retailer is below a given value, he can obtain higher profit than with the trade credit financing mode. The retailer's decision changes with the introduction of the discount rate in the supply chain. Bank financing becomes more attractive for the capital constrained retailer especially when the bank takes the leading position and discount rates verify the following relation $\left(\tau_{B}>\tau_{R}>\tau_{S}\right)$. Our results are therefore different from the results in perfect competitive market and stochastic demand environment, where Kouvelis and Zhao (2017) claim that trade credit is the best solution for the supply chain with capital constrained issue. However, our results are in line with Yang and Birge (2017) that confirm the importance to use bank credit as a complement to trade credit. Additionally, the supplier achieves the same profit in trade credit as in a situation with unlimited cash.

This work is subject to some limitations in its design, which could provide potential promising avenue of research. Future research could explore different forms (i) of price sensitive demand functions including stochastic factors as in Li et al. (2017), or (ii) of contracts as in Zhan et al. (2019). Our results are obtained in a non-cooperative game framework. It could be interesting to investigate the financing decision in a cooperative framework.

\section{Acknowledgment}

This work was funded by the research project RCSM, Risk, Credit Chain \& Supply Chain Management (FUI 15 of the French government) and by the research project FILEAS-FOG (ANR-17-CE10-0001-01). An initial version was presented to the french speaking conference CIGI in Montreal (2015).

\section{References}

Alan, Y. and Gaur, V. (2016). Operational investment and capital structure under asset-based lending. Technical report, Johnson School Research Paper Series.

Azar, J. M., Raina, S., and Schmalz, M. C. (2019). Ultimate ownership and bank competition. Technical report, Available at SSRN 2710252.

Babich, V. and Kouvelis, P. (2018). Introduction to the Special Issue on Research at the Interface of Finance, Operations, and Risk Management (iFORM): Recent Contributions and Future Directions. Manufacturing and Service Operations Management, 20(1):1-18.

Berger, A. and Udell, G. (1995). Relationship Lending and Lines of Credit in Small Firm Finance. The Journal of Business, 68(3):351-381.

Biais, B. and Gollier, C. (1997). Trade Credit and Credit Rationing. The Review of Financial Studies, 10(4):903-937.

Booth, L., Aivazian, V., Demirguc-Kunt, A., and Maksimovic, V. (2001). Capital Structures in Developing Countries. The Journal of Finance, 56(1):87-130.

Burkart, M. and Ellingsen, T. (2004). In-Kind Finance: A Theory of Trade Credit. American Economic Review, 94(3):569-590. 
Buzacott, J. and Zhang, R. (2004). Inventory Management with Asset-Based Financing. Management Science, 50(9):1274-1292.

Cai, G., Chen, X., and Xiao, Z. (2014). The roles of bank and trade credits: Theoretical analysis and empirical evidence. Production \& Operations Management, 23(4):583 $-598$.

Caldentey, R. and Chen, X. (2009). The role of financial services in procurement contracts. Handbook Of Integrated Risk Management In Global Supply Chains; Kouvelis, P., Boyabatli, O., Dong, L., Li, R., Eds.

Chen, L. H. and Kang, F. (2010). Integrated inventory models considering the two-level trade credit policy and a price-negotiation scheme. European Journal of Operational Research, 205(1):47-58.

Chen, S.-C. and Teng, J.-T. (2015). Inventory and credit decisions for time-varying deteriorating items with up-stream and down-stream trade credit financing by discounted cash flow analysis. European Journal of Operational Research, 243(2):566 -575 .

Chen, X. and Cai, G. (2011). Joint logistics and financial services by a 3pl firm. European Journal of Operational Research, 214(3):579 - 587.

Chen, X., Qi, L., Shen, Z.-J. M., and Xu, Y. (2020). The value of trade credit under risk controls. International Journal of Production Research, 0(0):1-24.

Chen, Z., Yuan, K., and Zhou, S. (2019). Supply chain coordination with trade credit under the cvar criterion. International Journal of Production Research, 57(11):35383553.

Cheng, Y., Wu, D. D., Olson, D. L., and Dolgui, A. (2020). Financing the newsvendor with preferential credit: bank vs. manufacturer. International Journal of Production Research, 0(0):1-20.

Corbett, C. J., Zhou, D., and Tang, C. S. (2004). Designing Supply Contracts: Contract Type and Information Asymmetry. Management Science, 50(4):550-559.

Dada, M. and Hu, Q. (2008). Financing newsvendor inventory. Operations Research Letters, 36(5):569-573.

Dammon, R. M. and Senbet, L. W. (1988). The effect of taxes and depreciation on corporate investment and financial leverage. The Journal of Finance, 43(2):357-373.

de Boer, R., Steeman, M., Gelsomino, L., and Perego, A. (2015). Coherent Decision Making in Supply Chain Finance: a Learning Approach. EUROMA Neuchatel 2015, pages 1-6.

Deng, S., Gu, C., Cai, G., and Li, Y. (2018). Financing multiple heterogeneous suppliers in assembly systems: Buyer finance vs. bank finance. Manufacturing \& Service Operations Management, 20(1):53-69.

Emery, G. W. (1987). An optimal financial response to variable demand. Journal of Financial and Quantitative Analysis, 22(2):209-225.

Frank, M. Z. and Maksimovic, V. (2005). Trade credit, collateral, and adverse selection. SSRN Electronic Journal.

Freixas, X. (1993). Short term credit versus account receivable financing. Universitat Pompeu Fabra, Department of Economics and Business, pages Working Paper No 27, .

Ghosh, D. and Shah, J. (2012). A comparative analysis of greening policies across supply chain structures. International Journal of Production Economics, 135(2):568 583.

Gupta, S. and Dutta, K. (2011). Modeling of financial supply chain. European Journal of Operational Research, 211(1):47-56.

Hofmann, E., Belin, O., et al. (2011). Supply Chain Finance Solutions. Springer. 
Hovhannisyan, V., Cho, C., and Bozic, M. (2019). Relationship between price and retail concentration: evidence from the us food industry. European Review of Agricultural Economics, 46:319 - 345.

Huang, Y. (2007). Optimal retailer's replenishment decisions in the EPQ model under two levels of trade credit policy. European Journal of Operational Research, 176(3):1577-1591.

Jain, N. (2001). Monitoring costs and trade credit. The Quarterly Review of Economics and Finance, 41(1):89-110.

Jin, W., Zhang, Q., and Luo, J. (2019). Non-collaborative and collaborative financing in a bilateral supply chain with capital constraints. Omega, 88:210 - 222.

Jing, B., Chen, X., and Cai, G. G. (2012). Equilibrium financing in a distribution channel with capital constraint. Production and Operations Management, 21(6):10901101.

Kouvelis, P. and Zhao, W. (2012). Financing the newsvendor: supplier vs. bank, and the structure of optimal trade credit contracts. Operations Research, 60(3):566-580.

Kouvelis, P. and Zhao, W. (2017). Who should finance the supply chain ? Impact of credit ratings on supply chain decisions. Manufacturing and Service Operations Management, 20(1):19-35.

Lariviere, M. A. and Porteus, E. L. (2001). Selling to the newsvendor: An analysis of price-only contracts. Manufacturing \& service operations management, 3(4):293305.

Lau, A. L. and Lau, H. (2003). Some two-echelon supply-chain games: Improving from deterministic-symmetric-information to stochastic-asymmetric-information models. European Journal of Operational Research, 161(1):203-223.

Lee, C. H. and Rhee, B. (2010). Coordination contracts in the presence of positive inventory financing costs. International Journal of Production Economics, 124(2):331 -339 .

Lee, C. H. and Rhee, B. (2011). Trade credit for supply chain coordination. European Journal of Operational Research, 214(1):136 - 146.

Li, Q., Li, B., Chen, P., and Hou, P. (2017). Dual-channel supply chain decisions under asymmetric information with a risk-averse retailer. Annals of Operations Research, 257(1-2):423-447.

Li, Y. and Jiang, X. (2020). The supplier's optimal guarantee policy in newsvendor finance. International Transactions in Operational Research, 27(5):2370-2395.

Mian, S. L. and Clifford, S. J. (1992). Accounts receivable management policy: theory and evidence. The Journal of Finance, 47(1):169-200.

Modigliani, F. and Miller, M. (1959). The cost of capital, corporation finance and the theory of investment. The American Economic Review, 49(4):655-669.

Ouyang, L.-Y., Yang, C.-T., Chan, Y.-L., and Cárdenas-Barrón, L. E. (2013). A comprehensive extension of the optimal replenishment decisions under two levels of trade credit policy depending on the order quantity. Applied Mathematics and Computation, 224:268 - 277.

Petersen, M. and Rajan, R. G. (1997). Trade credit: Theories and evidence. Review of Financial Studies, 10(3):661-691.

Pfohl, H., Hoffmann, E., and Elbert, R. (2003). Financial supply chain management. Logistik Management, 5(4):10 - 26.

Phan, D. A., Vo, T. L. H., and Lai, A. N. (2019). Supply chain coordination under trade credit and retailer effort. International Journal of Production Research, 57(9):26422655.

Qin, Y., Wang, R., Vakharia, A., Chen, Y., and Seref, M. (2011). The newsvendor 
problem: Review and directions for future research. European Journal of Operational Research, 213(2):361 - 374 .

Rhian, S. and Paola, L. (2014). Integrating financial and physical supply chains: the role of banks in enabling supply chain integration. International Journal of Operations and Production Management, 34(3):298-324.

Rym Ayadi, R., De Groen, W., Sassi, I., Mathlouthi, W., Rey, H., and Aubry, O. (2015). Banking business models monitor. Technical report, available at SSRN: https://ssrn.com/abstract $=2784334$.

Salhofer, K., Tribl, C., and Sinabell, F. (2011). Market power in austrian food retailing: the case of milk products. Empirica, 39:109 - 122.

Schwartz, R. A. and Whitcomb, D. K. (1977). Implicit Transfers In The Extension Of Trade Credit. Salomon Brothers Center for the Study of Financial Institutions.

Seifert, D., Seifert, R. W., and Protopappa-Sieke, M. (2013). A review of trade credit literature: Opportunities for research in operations. European Journal of Operational Research, 231(2):245-256.

Shah, N. H. and Cárdenas-Barrón, L. E. (2015). Retailer's decision for ordering and credit policies for deteriorating items when a supplier offers order-linked credit period or cash discount. Applied Mathematics and Computation, 259:569 - 578.

Srinivasa, R. and Mishra, V. K. (2011). Short-term financing in a cash-constrained supply chain. International Journal of Production Economics, 134(2):407-412.

Summers, B. and Wilson, N. (2002). An empirical investigation of trade credit demand. International Journal of the Economics of Business, 9(2):257-270.

Teng, J.-T., Min, J., and Pan, Q. (2012). Economic order quantity model with trade credit financing for non-decreasing demand. Omega, 40(3):328 - 335.

Tirole, J. (1988). The Theory Of Industrial Organization. MIT Press.

Tiwari, S., Cárdenas-Barrón, L. E., Khanna, A., and Jaggi, C. K. (2016). Impact of trade credit and inflation on retailer's ordering policies for non-instantaneous deteriorating items in a two-warehouse environment. International Journal of Production Economics, 176:154 - 169.

Wang, C., Fan, X., and Yin, Z. (2019). Financing online retailers: Bank vs. electronic business platform, equilibrium, and coordinating strategy. European Journal of Operational Research, 276(1):343 - 356 .

Wang, Q. and Zhang, B. (2020). A guarantee credit model with substitutable product competition. International Journal of Production Research, 0(0):1-22.

Wilner, B. S. (2000). The exploitation of relationships in financial distress: The case of trade credit. The Journal of Finance, 55(1):153-178.

Wu, J., Al-khateeb, F. B., Teng, J.-T., and Cárdenas-Barrón, L. E. (2016). Inventory models for deteriorating items with maximum lifetime under downstream partial trade credits to credit-risk customers by discounted cash-flow analysis. International Journal of Production Economics, 171:105 - 115.

Wu, J., Ouyang, L.-Y., Cárdenas-Barrón, L. E., and Goyal, S. K. (2014). Optimal credit period and lot size for deteriorating items with expiration dates under twolevel trade credit financing. European Journal of Operational Research, 237(3):898 $-908$.

Yan, N., Sun, B., Zhang, H., and Liu, C. (2016). A partial credit guarantee contract in a capital-constrained supply chain: Financing equilibrium and coordinating strategy. International Journal of Production Economics, 173:122 - 133.

Yang, S. A. and Birge, J. R. (2013). How inventory is (should be) financed: Trade credit in supply chains with demand uncertainty and costs of financial distress. Available at SSRN 1734682. 
Yang, S. A. and Birge, J. R. (2017). Trade credit, risk sharing, and inventory financing portfolios. Management Science, 64(8):3469-3970.

Yu, Y., Huang, G., and Guo, X. (2020). Financing strategy analysis for a multi-sided platform with blockchain technology. International Journal of Production Research.

Zhan, J., Chen, X., and Hu, Q. (2019). The value of trade credit with rebate contract in a capital-constrained supply chain. International Journal of Production Research, 57(2):379-396.

Zhang, Q., Dong, M., Luo, J., and Segerstedt, A. (2014). Supply chain coordination with trade credit and quantity discount incorporating default risk. International Journal of Production Economics, 153:352 - 360.

\section{Appendix A. Proofs for scenarios A and I (Proposition 3.1)}

The retailer profit function is: $\Pi_{R}=p q \tau_{R}-w q$

The derivative of the retailer profit function with respect to $q$ is: $\frac{\partial \Pi_{R}}{\partial q}=\frac{a}{b} \tau_{R}-\frac{2 q}{b} \tau_{R}-w$ Solving the following equation: $\frac{\partial \Pi_{R}}{\partial q}=0 \Rightarrow \frac{a}{b} \tau_{R}-\frac{2 q}{b} \tau_{R}-w=0$ gives $q=\frac{a \tau_{R}-b w}{2 \tau_{R}}$ and the second derivative is $\frac{\partial^{2} \Pi_{R}}{\partial q^{2}}=-\frac{2}{b} \tau_{R}<0$

The retailer's profit function is concave and he accepts an optimum for $q=\frac{a \tau_{R}-b w}{2 \tau_{R}}$, and the profit function becomes $\Pi_{R}=\frac{\left(a \tau_{R}-b w\right)^{2}}{4 b \tau_{R}}$.

For the supplier, the profit function is as follows: $\Pi_{S}=(w-c) q$ subject to the retailer's cash $T \leq w q$. The optimization of this problem will be solved using a Lagrangian method.

The Lagrangian is equal to: $L_{S}=(w-c) q-\lambda(T-w q)$ with $q=\frac{a \tau_{R}-b w}{2 \tau_{R}}$

The Lagrangian becomes: $L_{S}=(w-c) \frac{a \tau_{R}-b w}{2 \tau_{R}}-\lambda\left(T-w \frac{a \tau_{R}-b w}{2 \tau_{R}}\right)$

The Kuhn-Tucker conditions are:

1) $\frac{\partial L_{S}}{\partial w}=0$

2) $\lambda(T-w q)=0$

3) $\lambda \geq 0$

4) $\frac{\partial L_{S}}{\partial w} \geq 0$

The first condition of Kuhn-Tucker $\frac{\partial L_{S}}{\partial w}=0$

$\frac{\partial L_{S}}{\partial w}=\frac{a}{2}-\frac{w b}{\tau_{R}}+\frac{b c}{2 \tau_{R}}-\lambda\left(\frac{w b}{\tau_{R}}-\frac{a}{2}\right)$ solving this $\frac{\partial L_{S}}{\partial w}=0 \Rightarrow \frac{a}{2}-\frac{w b}{\tau_{R}}+\frac{b c}{2 \tau_{R}}-\lambda\left(\frac{w b}{\tau_{R}}-\frac{a}{2}\right)=0$ $\frac{a}{2}(1+\lambda)-\frac{w b}{\tau_{R}}(1+\lambda)+\frac{b c}{2 \tau_{R}}=0 \Rightarrow w=\frac{a \tau_{R}(1+\lambda)+b c}{2 b(1+\lambda)}$

The second condition of Kuhn-Tucker for $\lambda(w q-T)=0$, the cases of study are $\lambda=0$ and/or $w q-T=0$

$\lambda=0$ implies $w=\frac{a \tau_{R}+b c}{2 b}$ and $q=\frac{a \tau_{R}-b c}{4 \tau_{R}}$ then $\Pi_{R}=\frac{\left(a \tau_{R}-b c\right)^{2}}{16 b \tau_{R}}$ and $\Pi_{S}=\frac{\left(a \tau_{R}-b c\right)^{2}}{8 b \tau_{R}}$ these are the results of the scenario A.

$w q-T=0$ implies $w=\frac{T}{q}$, with $q=\frac{a \tau_{R}-b w}{2 \tau_{R}}$ the wholesale price is $w=\frac{2 \tau_{R} T}{a \tau_{R}-b w}$ thus $b w^{2}-w a \tau_{R}+2 \tau_{R} T=0$ the resolution of this equation gives $w=\frac{a \tau_{R} \pm \sqrt{\left(a \tau_{R}\right)^{2}-8 \tau_{R} b T}}{2 b}$.

If $w=\frac{a \tau_{R}-\sqrt{\left(a \tau_{R}\right)^{2}-8 \tau_{R} b T}}{2 b} \Rightarrow \Pi_{S}=T-\frac{c}{4 \tau_{R}}\left(a \tau_{R}+\sqrt{\left(a \tau_{R}\right)^{2}-8 \tau_{R} b T}\right)$

If $w=\frac{a \tau_{R}+\sqrt{\left(a \tau_{R}\right)^{2}-8 \tau_{R} b T}}{2 b} \Rightarrow \Pi_{S}=T-\frac{c}{4 \tau_{R}}\left(a \tau_{R}-\sqrt{\left(a \tau_{R}\right)^{2}-8 \tau_{R} b T}\right)$

The optimal wholesale price is $w=\frac{a \tau_{R}+\sqrt{\left(a \tau_{R}\right)^{2}-8 \tau_{R} b T}}{2 b}$ then $q=\frac{a \tau_{R}-\sqrt{\left(a \tau_{R}\right)^{2}-8 \tau_{R} b T}}{4 \tau_{R}}$ we substitute these optimal variables into the profit functions, therefore the optimal functions of the scenario I are: 
$\Pi_{S}=T-\frac{c}{4 \tau_{R}}\left(a \tau_{R}-\sqrt{\left(a \tau_{R}\right)^{2}-8 \tau_{R} b T}\right)$ and $\Pi_{R}=\frac{\left(a \tau_{R}-\sqrt{\left(a \tau_{R}\right)^{2}-8 \tau_{R} b T}\right)^{2}}{16 b \tau_{R}}$

\section{Appendix B. Proofs for Sc F (Proposition 3.2)}

In the non-cooperative game, the retailer optimizes his profit function $\Pi_{R}=p q \tau_{R}-$ $q\left(\alpha w_{0}+(1-\alpha) w_{1} \tau_{R}\right)$ under the constraint $T \geq \alpha w_{0} q$ (Step 1). The results of the retailer's optimization are sent to the supplier as a signal for his optimization $\Pi_{S}=$ $\alpha w_{0} q+\tau_{S}(1-\alpha) w_{1} q-c q($ Step 2).

Step 1: Retailer's optimization will be done by the Lagrangian:

$$
L_{R}=p q \tau_{R}-q\left(\alpha w_{0}+(1-\alpha) w_{1} \tau_{R}\right)-\lambda\left(\alpha w_{0} q-T\right)
$$

The FOC conditions of Kuhn and Tucker are:

- $\quad \frac{\partial L_{R}}{\partial q}=-w_{0} \alpha(1+\lambda)+\frac{\tau_{R}\left(a-2 q+b w_{1}(\alpha-1)\right.}{b}=0$

- $\quad \frac{\partial L_{R}}{\partial \alpha}=-q w_{0}(1+\lambda)+q w_{1} \tau_{R}=0$

- $\quad \lambda \frac{\partial L_{R}}{\partial \lambda}=0$

- $\quad \lambda \geq 0$

- $\frac{\partial L_{R}}{\partial \lambda} \geq 0$

These conditions lead to two cases:

(Case a) $\lambda>0 \Rightarrow \alpha w_{0} q=T$. Then $q=\frac{a-b w_{1}}{2}, \alpha=\frac{2 T}{w_{0}\left(a-b w_{1}\right)}$ and $\lambda=\frac{w_{1} \tau_{R}}{w_{0}}-1$. To respect the hypothesis $\lambda>0$, we have $w_{1} \tau_{R}>w_{0}$.

(Case b) $\lambda=0 \Rightarrow q=\frac{a-b w_{1}}{2}$ and $w_{0}=w_{1} \tau_{R}$. Moreover, $\alpha$ verifies $\alpha w_{0} q \leq T$ where $\alpha \in[0,1]$.

Step 2: The supplier's optimization is constrained by the retailer's signal. Two cases then occur:

(Case $a^{\prime}$ ) From the results obtained in case a, the supplier's profit is maximized for $\frac{\partial \Pi_{S}}{\partial w_{0}}=0$ and $\frac{\partial \Pi_{S}}{\partial w_{1}}=0$. We obtain $w_{0}=\frac{2 T \tau_{S}}{a \tau_{S}+b c}$ and $w_{1}=0$ which contradicts the constraint $w_{0}<w_{1} \tau_{R}$.

(Case b') the constraint is $\alpha w_{0} q \leq T$, and the supplier's Lagrangian is: $L_{S}=\left(\alpha w_{0} q+\right.$ $\left.\tau_{S}(1-\alpha) w_{1} q-c q\right)-\lambda\left(\alpha w_{0} q-T\right)$.

Then, the FOC conditions of Kuhn and Tucker are: $\frac{\partial L_{S}}{\partial w_{0}}=0, \frac{\partial L_{S}}{\partial \alpha}=0, \lambda \frac{\partial L_{S}}{\partial \lambda}=0$, $\lambda \geq 0$ and $\frac{\partial L_{S}}{\partial \lambda} \geq 0$. Three results are obtained:

(Case b'1) $\lambda=0, w_{0}=\frac{a \tau_{R}}{b}$ and $\alpha=-\frac{a \tau_{S}-b c}{a\left(\tau_{R}-\tau_{S}\right)}$ which implies $q=0$. Hence the supplier's function is null $\Pi_{S}=0$.

(Case b'2) $\lambda=0, w_{0}=0 \Rightarrow w_{1}=0$ and $\alpha=\frac{a \tau_{S}+b c}{a\left(\tau_{S}-\tau_{R}\right)}$ which implies $\Pi_{S}=-c q<0$.

(Case b'3) $\lambda=1-\frac{\tau_{S}}{\tau_{R}}, w_{0}=\frac{\left(a \tau_{S}+b c\right) \tau_{R}}{2 b \tau_{S}}$ and $\alpha=\frac{8 b T \tau_{S}^{2}}{\left(\left(a \tau_{R}\right)^{2}-(b c)^{2}\right) \tau_{R}}$. This result is admissible only if $\tau_{S} \leq \tau_{R}$ (which appears as a necessary condition in the Proposition).

To verify the second order conditions (SOC), we need to calculate the bordered Hessian matrix for the solutions obtained:

$$
H_{S}=\left(\begin{array}{ccc}
0 & \frac{\partial\left(T-\alpha w_{0} q\right)}{\partial w_{0}} & \frac{\partial\left(T-\alpha w_{0} q\right)}{\partial \alpha} \\
\frac{\partial\left(T-\alpha w_{0} q\right)}{\partial w_{0}} & \frac{\partial^{2} L_{S}}{\partial w_{0}^{2}} & \frac{\partial^{2} L_{S}}{\partial w_{0} \partial \alpha} \\
\frac{\partial\left(T-\alpha w_{0} q\right)}{\partial \alpha} & \frac{\partial^{2} L_{S}}{\partial w_{0} \partial \alpha} & \frac{\partial^{2} L_{S}}{\partial \alpha^{2}}
\end{array}\right)
$$


As the only constraint $T=\alpha w_{0} q$ is saturated, we calculate the determinant of $H$, that is:

$$
\begin{gathered}
D H_{S}=\left|\begin{array}{ccc}
0 & -\frac{2 b T \tau_{S}}{\left(a \tau_{S}+b c\right) \tau_{R}} & -\frac{\left(a \tau_{S}\right)^{2}-(b c)^{2}}{8 b \tau_{S}^{2}} \tau_{R} \\
-\frac{2 b T \tau_{S}}{\left(a \tau_{S}+b c\right) \tau_{R}} & -\frac{b \tau_{S}}{\tau_{R}^{2}} & 0 \\
-\frac{\left(a \tau_{S}\right)^{2}-(b c)^{2}}{8 b \tau_{S}^{2}} \tau_{R} & 0 & 0
\end{array}\right| \\
=\frac{b \tau_{S}}{\tau_{R}^{2}}\left(\frac{\left(a \tau_{S}\right)^{2}-(b c)^{2}}{8 b \tau_{S}^{2}} \tau_{R}\right)^{2}>0
\end{gathered}
$$

As $\operatorname{sign}\left(D H_{S}\right)=\operatorname{sign}(-1)^{n}$ (with $n=2$ the number of variables), this solution is a maximum for the supplier.

Similarly, we verify that the SOCs are verified for the retailer (case b'3). The constraint $T \geq \alpha w_{0} q$ is not saturated and we calculate the two last principal minors of the Hessian matrix.

$$
H_{R}=\left(\begin{array}{cc}
-\frac{2 \tau_{R}}{b} & 0 \\
0 & 0
\end{array}\right)
$$

We have $-\frac{2 \tau_{R}}{b}<0$ and $D H_{R}=0 \Rightarrow \operatorname{Tr}\left(H_{R}\right)<0$, where $\operatorname{Tr}\left(H_{R}\right)$ is the Hessian matrix trace. The solution is then a maximum for the retailer.

\section{Appendix C. Proofs for Sc B1 (bank leader credit)}

In the non-cooperative game, the retailer optimizes his profit function $\Pi_{R}=p q \tau_{R}-T-(w q-T) \tau_{R}\left(1+r_{B 1}\right)$ under the cash holdings constrain $T<w q$ (Step 1) based on the result obtained, the supplier will optimize his profit function (Step 2). Finally, the bank will use the result of the supplier's optimization as a signal for his optimization (Step 3).

Step 1 The retailer's optimization

The Lagrangian of this optimization is:

$L_{R}=p q \tau_{R}-T-(w q-T) \tau_{R}\left(1+r_{B 1}\right)-\lambda(T-w q)$. The Kuhn-Tucker conditions are:

1) $\frac{\partial L_{R}}{\partial q}=0$

2) $\lambda(T-w q)=0$

3) $\quad \lambda \geq 0$

4) $\lambda \frac{\partial L_{R}}{\partial \lambda} \geq 0$

The Kuhn-Tucker conditions give:

(Case a) $\lambda>0 \Rightarrow q=\frac{T}{W}$ which contradicts the constraint $T<w q$.

(Case b) $\lambda=0 \Rightarrow q=\frac{a-b w\left(1+r_{B 1}\right)}{2}$ which verifies the Kuhn-Tucker conditions.

The constraint $T<w q$ is not saturated, hence the concavity is checked by $\frac{\partial^{2} L_{R}}{\partial q^{2}}=-\frac{2 \tau_{R}}{b}<0$.

In consequence, the retailer's profit function is concave and accepts a maximum in 
$q=\frac{a-b w\left(1+r_{B 1}\right)}{2}$.

Step 2 the supplier's optimization

The supplier function $\Pi_{S}=w q-c q$ : we inject the optimum value of the retailer's order quantity $q=\frac{a-b w\left(1+r_{B 1}\right)}{2}$ into the supplier profit function and optimize this function.

$\frac{\partial \Pi_{S}}{\partial w}=\frac{a}{2}-b w\left(1+r_{B 1}\right)+\frac{b c\left(1+r_{B 1}\right)}{2}$

By solving this $\frac{\partial \Pi_{S}}{\partial w}=0$ we obtain $w=\frac{a+b c\left(1+r_{B 1}\right)}{2 b\left(1+r_{B 1}\right)}$ and $\frac{\partial^{2} \Pi_{S}}{\partial w^{2}}=-b\left(1+r_{B 1}\right) \leq 0$ then $w=\frac{a+b c\left(1+r_{B 1}\right)}{2 b\left(1+r_{B 1}\right)}$ is an optimum supplier's wholesale price.

Step 3 the bank's optimization

Let the bank problem be $\Pi_{B}=-(w q-T)+(w q-T)\left(1+r_{B 1}\right) \tau_{B}$.

The retailer's working capital constraint $w q>T$ makes the bank credit available, and $\tau_{B}\left(1+r_{B 1}\right)-1>0$ ensures a positive bank payoff. To fix an optimal bank interest rate $r_{B 1}$ we follow the two steps described below:

We have $\frac{\partial(T-w q)}{\partial r_{B 1}}=-b\left(\frac{c^{2}}{8}+\frac{8 a^{2}}{\left(8 b+8 b r_{B 1}\right)^{2}}\right)<0$ hence $T-w q$ is decreasing with $r_{B 1}$. Consequently, there exists an interest rate $r_{B 1}$ which verifies $T=w q$

with $q=\frac{a-b c\left(1+r_{B 1}\right)}{4}$ and $w=\frac{a+b c\left(1+r_{B 1}\right)}{2 b\left(1+r_{B 1}\right)}$ we obtain the equation $\frac{a^{2}-(b c)^{2}\left(1+r_{B 1}\right)^{2}}{8 b\left(1+r_{B 1}\right)}=$ $T$. The resolution gives the following results: $r_{B 1}^{S 1}=\frac{-\left[(b c)^{2}+4 b T\right]+b \sqrt{(a c)^{2}+16 T^{2}}}{(b c)^{2}} r_{B 1}^{S 2}=$ $\frac{-\left[(b c)^{2}+4 b T\right]-b \sqrt{(a c)^{2}+16 T^{2}}}{(b c)^{2}}$.

Furthermore, $\left(1-\left(1+r_{B 1}\right) \tau_{B}\right)$ is increasing depending on $r_{B 1}$, hence there exists an interest rate where $\left(1-\left(1+r_{B 1}\right) \tau_{B}\right)=0$ which gives $r_{B 1}^{S 3}=\frac{1-\tau_{B}}{\tau_{B}}$

In addition, $\frac{\partial^{2} \Pi_{B}}{\partial r_{B 1}^{2}}<0$ when $r_{B 1}>-1$ and $\Pi_{B}\left(r_{B 1}^{S 1}\right)=\Pi_{B}\left(r_{B 1}^{S 3}\right)=0$. Then, there exists a unique optimal bank interest rate which is the resolution of $\frac{\partial \Pi_{B}}{\partial r_{B 1}}=0$, that is:

$$
-a^{2}+\left(8 b T \tau_{B}-(b c)^{2}\right)\left(1+r_{B 1}\right)^{2}+2(b c)^{2}\left(1+r_{B 1}\right)^{3} \tau_{B}=0
$$

This Equation (1) can be solved using the Cardan method.

\section{Appendix D. Proof of Proposition 3.4}

Based on the implicit function theorem we have:

$\partial r_{B 1} / \partial T=-\frac{G_{T}}{G_{r_{B 1}}}$, where $G\left(r_{B 1}, T\right)$ is the Equation (1), and $G_{i}=\frac{\partial G\left(r_{B 1}, T\right)}{\partial i}$, $i \in\left\{T, r_{B 1}\right\}$

$\partial r_{B 1} / \partial T=\frac{4\left(1+r_{B 1}\right) \tau_{S}}{b c^{2}\left(1-3\left(1+r_{B 1}\right) \tau_{B}\right)-8 T \tau_{B}}<0$. Hence, the bank interest rate decreases with the retailer's cash holdings, based on the bank condition $\tau_{B}\left(1+r_{B 1}\right)-1>0$.

$\partial r_{B 1} / \partial \tau_{B}=-\frac{G_{\tau_{B}}}{G_{r_{B 1}}}$, where $G\left(r_{B 1}, \tau_{B}\right)$ is the Equation (1).

$\partial r_{B 1} / \partial \tau_{B}=\frac{\left(1+r_{B 1}\right)\left(4 T+b c^{2}\left(1+r_{B 1}\right)\right)}{b c^{2}\left(1-3\left(1+r_{B 1}\right) \tau_{B}\right)-8 T \tau_{B}}<0$. Hence, the bank interest rate decreases with the bank discount rate factor. Therefore, the bank interest rate is increasing with the bank discount rate. 


\section{Appendix E. Proof for Sc B2 (bank subleader credit)}

In this scenario, the retailer optimizes his profit function (step 1); the optimal retailer's order quantity will be used for the bank's optimization (step 2); finally, the supplier determines the optimal wholesale price based on the bank's and retailer's optimal decision variables.

Step 1 Retailer's profit

This optimization is constrained by the cash's level. The Lagrangian is therefore: $L_{R}=p q \tau_{R}-T-(w q-T) \tau_{R}\left(1+r_{B 2}\right)-\lambda(T-w q)$. FOCs are:

1) $\frac{\partial L_{R}}{\partial q}=0$

2) $\lambda(T-w q)=0$

3) $\lambda \geq 0$

4) $\lambda \frac{\partial \bar{L}_{R}}{\partial \lambda} \geq 0$

The Kuhn-Tucker conditions give:

(Case a) $\lambda>0 \Rightarrow q=\frac{T}{w}$ which contradict the constraint $T<w q$.

(Case b) $\lambda=0 \Rightarrow q=\frac{a-b w\left(1+r_{B 2}\right)}{2}$ which verifies all conditions. In this case, constraint $T<w q$ is not saturated and SOC is verified: $\frac{\partial^{2} L_{R}}{\partial q^{2}}=-\frac{2 \tau_{R}}{b}<0$.

Step 2 Bank's profit

The bank profit function is: $\Pi_{B}=(w q-T)\left(\left(1+r_{B 2}\right) \tau_{B}-1\right)$. Each member must be positive. We then define the Lagrangian function: $L_{B}=$ $(w q-T)\left(\left(1+r_{B 2}\right) \tau_{B}-1\right)-\lambda_{1}(T-w q)-\lambda_{2}\left(-\left(1+r_{B 2}\right) \tau_{B}+1\right)$. FOCs are:

1) $\frac{\partial L_{B}}{\partial r_{B 2}}=0$

2) $\quad \lambda_{1}(T-w q)=0$ and $\lambda_{2}\left(-\left(1+r_{B 2}\right) \tau_{B}+1\right)=0$

3) $\lambda_{1} \geq 0$ and $\lambda_{2} \geq 0$

4) $\lambda_{1} \frac{\partial L_{B}}{\partial \lambda_{1}} \geq 0$ and $\lambda_{2} \frac{\partial L_{B}}{\partial \lambda_{2}} \geq 0$

FOC conditions are verified for $\left(1+r_{B 2}\right)=\frac{a \tau_{B}+b w}{2 b w \tau_{B}}-\frac{T}{b w^{2}}$ and $\lambda_{1}=\lambda_{2}=0$. In this case, $\frac{\partial^{2} L_{B}}{\partial r_{B 2}^{2}}=-b w^{2} \tau_{B}<0$ which verifies the SOC conditions.

Step 3 Supplier's profit

Given $q=\frac{a-b w\left(1+r_{B 2}\right)}{2}$ and $\left(1+r_{B 2}\right)=\frac{a \tau_{B}+b w}{2 b w \tau_{B}}-\frac{T}{b w^{2}}$, the supplier's profit is: $\Pi_{S}=$ $(w-c) q=(w-c)\left(\frac{a \tau_{B}-b w}{4 \tau_{B}}+\frac{T}{2 w}\right)$.

The result is obtained from the two following items:

1) $\frac{\partial \Pi_{S}}{\partial w}=\frac{a w^{2} \tau_{B}+2 c T \tau_{B}+b w^{2}(c-2 w)}{4 w^{2} \tau_{B}}=0$

2) $\frac{\partial^{2} \Pi_{S}}{\partial w^{2}}=-\frac{b}{2 \tau_{B}}-\frac{T c}{2 w^{3}}<0$ with $w>0$.

\section{Appendix F. Proof of Proposition 3.5)}

Given $q=\frac{a-b w\left(1+r_{B 2}\right)}{2}$ and $\left(1+r_{B 2}\right)=\frac{a \tau_{B}+b w}{2 b w \tau_{B}}-\frac{T}{b w^{2}}$, the total purchase is defined by $w q=\frac{a w^{2} \tau_{B}-b w^{3}+2 T \tau_{B}}{4 w \tau_{B}}$. We obtain:

1) $(w q-T)>0$ for $T=0$.

2) $\frac{\partial(w q-T)}{\partial T}<0$

3) $\frac{\partial^{2}(w q-T)}{\partial T^{2}}<0$

There exists then a maximum $T_{B 2}$ (solution of $w q-T=0$ ) above which the retailer will not use a bank credit. 